\title{
Failure of laboratory evaluation of CAI to generalize to classroom settings: The SuperShrink interview simulation
}

\author{
JOSEPH LOWMAN \\ University of North Carolina, Chapel Hill, North Carolina
}

\begin{abstract}
Laboratory settings are often used to evaluate instructional innovations. This paper reports a comparison of laboratory and course evaluation of SuperShrink, an educational computer simulation of two comprehensive clinical interviews designed to teach undergraduates personality and diagnostic formulation. Previous experimental comparison of the computer simulation with a booklet version of SuperShrink in a laboratory setting, carried out with volunteers from the departmental subject pool, indicated that students found the computer version more involving, enjoyable, and realistic. The present experiment involved the comparison of computer and booklet versions of two complete cases in four courses in abnormal psychology. The results opposed those from the laboratory setting. The students strongly preferred the booklet version and cited its greater convenience as one reason for their preference. Our findings suggest that care must be taken to ensure that laboratory evaluations of CAI are ecologically valid and are replicated in classroom settings.
\end{abstract}

SuperShrink (Lowman, 1987, 1990) is an educational simulation of a clinical interview with the student as interviewer and the computer as client. Unlike previous simulations of a person, such as Weizenbaum's ELIZA (Weizenbaum, 1976) or Colby's PARA (Colby, 1975, 1980; Colby, Watt, \& Gilbert, 1966), SuperShrink's purposes are educational rather than metaphysical; that is, no attempt is made to convince students that they are speaking with a real person. Objectives are to increase the complexity with which undergraduates combine observations, social history information, and theoretical constructs in formulating and writing a comprehensive case history. For each case, students typically devote 5-8 h of terminal time to the interviewing and an additional 5-10 $\mathrm{h}$ writing 10 - to 15 -page diagnostic and personality formulation reports. There are two simulations: "Victor" (Lowman, 1987) and "Jennifer" (Lowman, 1990).

\footnotetext{
This research was supported by a grant from IBM, Inc. Appreciation to William Graves for his help in obtaining that support is acknowledged. Appreciation is also expressed to my colleagues Donald Baucom, Linda Craighead, Bernadette Gray-Little, and Barclay Martin for allowing their students to participate in this research, and to Johanna Merritt for her assistance in data entry and analysis. Michael Phillips, John Mundt, Grant Vinik, and Wendi Thomas also made an important contribution by developing and applying an objective system for rating students' term papers. Inquiries about SuperShrink or this research should be addressed to Joseph Lowman, Department of Psychology, CB 2370, Davie Hall, University of North Carolina, Chapel Hill, NC 27599-3270 (ULOWMA@UNC.BITNET).
}

Informal evaluation of these simulated case studies in personality, abnormal, and general psychology courses indicates that students become very engaged in choosing content areas, typing questions selected from a menu, reading the first-person answers, and making sense of the wealth of complex and sometimes contradictory information provided. Instructors also positively review the software, especially students' enthusiasm for the activity and the high quality of their written reports. Experimental analyses of students' attraction to the software in laboratory settings helped select design features (Lowman \& Norkus, 1987) and suggested that the computer is essential to student satisfaction (Sussman \& Lowman, 1989). The present experimental evaluation in a classroom setting, however, reveals serious limitations in the SuperShrink laboratory analogues used previously and suggests potential limitations in laboratory evaluations of other forms of computer-assisted instruction (CAI).

\section{PREVIOUS SUPERSHRINK LABORATORY STUDIES}

Lowman and Norkus (1987) experimentally compared three methods of giving students information from simulated questions and answers: (1) typing-students read questions on a menu and typed them on the keyboard, and the client's answer was produced a few seconds later; (2) menu-students simply typed in the menu item number to produce the question and answer; and (3) returnstudents pressed the return key after each answer, and a new question and the resulting answer were produced 
after a standard delay period. Between-group comparisons indicated that the students greatly preferred the typing condition, reporting that it enhanced the realism of the simulation. A secondary within-subjects comparison-after rating the first method of viewing information, the students experienced each of the others in a counterbalanced ordersupported the students' strong preference for the typing condition, so it was used in the final publisher versions of the software. This finding, that activity required in the typing condition resulted in greater involvement and contributed to its appeal, has been reported in other CAI studies (Roblyer, 1985). It is important to note that the 90 volunteer subjects from the psychology department's subject pool were not required to write reports, and that they were given an abbreviated version of the case study, which contained 3 rather than 17 content areas.

Sussman and Lowman (1989) compared the same abbreviated CAI version of the first SuperShrink case with a version in which students read the questions and corresponding answers in a booklet. The two purposes of this experiment were to assess how essential the computer was to the positive evaluations given SuperShrink and to investigate active versus passive manipulation of the instructional materials. The computer and hard-copy versions presented identical information arranged in the same way on the screen or page; the primary difference was that the computer client's words appeared on a color screen one phrase at a time. An active-passive comparison (greater or lesser manipulation of the computer keyboard or a pencil) was also made. As in the previous study, the 120 subjects were from the departmental subject pool and were not required to write reports.

Sussman and Lowman (1989) reported a greater sense of control in the active conditions, and more involvement, enjoyment, and realism in the computer conditions. The computer appeared to contribute to the students' satisfaction with SuperShrink.

\section{CLASSROOM COMPARISON OF COMPUTER AND HARD-COPY CASES}

In the present study, Sussman and Lowman's (1989) comparison of computer and hard-copy case information was extended to classroom settings in which two complete SuperShrink cases were used. Students in four sections of abnormal psychology completed the simulated interviews and wrote graded reports in various combinations of conditions. For both cases, one section used the computer and another used written booklets; two sections used the computer for one case and the booklets for the other, but in reversed order. It was hypothesized that, for each case, students would rate the computer version higher on involvement, enjoyment, and realism.

\section{Method}

Subjects. Four instructors of abnormal psychology at the University of North Carolina at Chapel Hill (all senior faculty members with 8-35 years of teaching experience) assigned two SuperShrink papers to their students during the fall semester of 1988 and encouraged their students to volunteer to participate in the research by allowing their SuperShrink papers to be photocopied for later analysis and by completing an evaluation questionnaire after submitting each paper. The students had no choice about completing the interviews and writing the papers, but they were free to decline participation in the research. Prizes of SuperShrink T-shirts, $\$ 25, \$ 50$, and $\$ 100$ were offered as inducements and awarded randomly to students whose data were submitted on time. Of the 159 enrolled students, 117 (74\%) agreed to participate. The author graded all papers for the participating faculty, in order to reward their participation as well.

Materials. The students in computer conditions were loaned copies of the SuperShrink software and given information on the availability of public MS-DOS machines on campus. The students in the hard-copy condition were loaned attractive spiral-bound booklets containing questions and answers for each of the 17 content areas, each area marked by colored tabs protruding from the side of the booklet. The booklets contained the same information on case formulation and report writing as that which appears in the SuperShrinks' Interviewing Workbook that accompanies the software. No standard order was suggested for covering the various kinds of content for either condition; the students were instructed to follow their interests in reading through the 300 or so suggested questions and answers for each case.

Measures. Using evaluation questionnaires after each case report, the students noted their satisfaction with the interview instruction, using a 7-point Likert scale, on which " 1 " indicated the greatest satisfaction (as used by Lowman \& Norkus, 1987, and Sussman \& Lowman, 1989):

1. How involved were you in your interview with Victor? (or Jennifer)

2. How much did you enjoy your interview?

3 . How often were you bored during the interview?

4. How much control did you feel you had during the interview process?

5. How easy was it for you to make believe this was an actual interview?

A 10-item multiple-choice exam covering important biographical details for each case was also used to assess fundamental student knowledge of the case materials, more in order to ascertain whether or not students completed the entire interview than to evaluate learned skills. The students' term papers were rated using systematic ratings of the (1) comprehensiveness of content coverage, (2) complexity of reasoning demonstrated, and (3) clarity of style; these were then combined into an overall score. This objective system for rating SuperShrink papers was developed in previous research (Phillips, 1989).

Procedure. All students in the four classes completed the first interview under the randomly assigned condition, submitted 8- to 12-page written reports, and were given the first evaluation questionnaire. The graded reports were returned within 2 weeks, and the students were loaned materials for the second case. No students or instructors were told which condition was to be used for the second 
case until all measures concerning the first case were collected. A similar procedure was used to assess student learning and satisfaction with the second case. Cash prizes were not awarded until satisfaction data were received from the second case, although one $\mathrm{T}$-shirt was given to a randomly selected student from each class as a vicarious reinforcer after the first evaluation questionnaires were completed. Photocopies of students' papers were rated independently during a subsequent semester by two of three advanced psychology students trained in Phillips's (1989) scoring system.

\section{Results}

A multivariate analysis of variance (MANOVA) comparison of computer versus booklet presentation method for satisfaction ratings of the first case study yielded a highly significant effect [Wilks's lambda, $F(5,92)=6.91$, $p<.001]$. Significant univariate tests were found for ratings of enjoyment $[F(1,96)=6.67, p<.01]$ and boredom $[F(1,96)=29.75, p<.001]$. Repeat analyses covarying on total SAT scores and overall GPA reduced the strength of these comparisons slightly but did not change significance levels for the first case. Mean enjoyment ratings (4.80 and 5.35 for computer classes, and 5.68 and 5.48 for booklet classes) and boredom ratings (4.08 and 3.41 for computer classes, and 2.48 and 2.48 for booklet classes) showed that students greatly preferred the booklet version of the first case. Identical analyses for ratings of the second case showed a weaker overall effect [Wilks's lambda, $F(5,80)=2.35, p<.05]$ and a significant univariate effect only for enjoyment $[F(1,84)=4.64$, $p<.05]$. The pattern of mean satisfaction ratings for the second case was in the same direction as for the first, showing continued, albeit weaker, student preference for the booklet condition. Comparison of classes on minimal content knowledge showed no differences between the classes for either case.

Inspection of an open-ended question asking students in the two classes experiencing each method of case presentation which one they preferred showed that 5 students preferred the computer version and 32 preferred the booklet. Their explanations pointed overwhelmingly to issues of convenience; the booklet version was seen as quicker and easier to use.

Comparison of classes on potential moderator variables revealed an unanticipated selection effect that weakened the internal validity and may have influenced the results. The students in the section using the booklet version for both cases were found to have much higher SAT scores and GPAs ( $M=1,312$ and 3.59, respectively) than the students in the other classes $(M=1,123,1,124$, and 1,132 , and 2.95, 2.87, and 2.99, respectively). Multivariate and univariate comparisons of these two variables were extremely significant $(p s<.0001)$. Subsequent inquiry with the course instructor revealed that this section was open only to honors students.

Analysis of paper ratings for the first case produced strong interrater reliability coefficients of .95 for content, .89 for reasoning, .83 for writing clarity, and .95 for over- all scores. Reliability was weaker for ratings of papers based on the second case $(.79, .77, .37$, and .75 , respectively). Using paper grades given by the author without knowledge of individual students or experimental conditions as an external criterion, concurrent validity coefficients for overall paper scores based on the first case were moderately strong (.58 for one rater and .61 for the second rater). Validity coefficients for the second case were much lower (.38 and .34). Nonsignificant MANOVA comparisons of the computer versus paper conditions were found for each case ("Victor"' Wilks's lambda $=.944$, $d f=4,86$; "Jennifer"' Wilks's lambda $=.952, d f=4,79$ ). The experimental manipulations had no effect on the quality of term papers as measured by the systematic ratings.

\section{Discussion}

These results strongly demonstrate the importance of evaluating CAI in conditions as close as possible to their eventual application. Sussman and Lowman's (1989) laboratory comparison done with student volunteers apparently omitted two critical elements from the SuperShrink experience: the amount of time required to complete the entire interview, and the importance of graded written reports. In the context of students' lives, a 1- or 2-h laboratory experience with known time commitment and a lack of important consequences is not comparable to a 10- to 15-h graded assignment. In retrospect, finding that issues of convenience are more powerful in an ecologically valid setting should not be surprising (see Brunswik, 1956).

Similar inconsistencies have been found in the results of studies of simulated decision-making in laboratory versus real-world settings. For example, judges' bailsetting behavior in a laboratory simulation was in line with official bail guidelines in being most influenced by the defendants' degree of ties to the local community. In actual courtroom settings where they did not know they were being studied, the same judges made quite different decisions about bail, this time being most influenced by district attorneys' recommendations and only slightly by local ties (Ebbesen \& Konecni, 1975). Inconsistencies have also been identified between real-world and laboratory simulations of felon sentencing, automobile driver behavior, and swine judging (see summaries by Ebbesen \& Konecni, 1980). The identification of these inconsistencies does not argue against the use of tightly controlled laboratory studies of decision-making but rather for the necessity of extending the external validity of such studies empirically through real-world comparisons. Otherwise, important variables affecting real-world decision-making may be omitted from laboratory analysis, or phenomena (such as conservatism in probability revision) may be identified that are artifacts of the laboratory simulation (Winkler \& Murphy, 1973) and unseen in real-world settings.

The present study illustrates both the disadvantages and advantages of classroom versus laboratory evaluation of CAI. Internal validity was no doubt compromised by the unknown inclusion of an honors section, which by chance used booklets for both cases. Conceivably, more capable 
students may have had different preferences for the two instructional methods, though outcome data from those students were indistinguishable from others using the booklets. Even with careful planning, field experiments present a greater likelihood of unknown selection effects' lowering confidence in observed results. Nonetheless, the strength of findings in this study and the fact that other classes also using the booklets showed the same pattern of ratings (nonsignificant MANOVA comparisons were obtained for each case) suggest that the unfortunate selection effect had little effect on the conclusions that students preferred the booklet version of the SuperShrink case information.

For neither case did the computer-booklet manipulation appear to affect what students learned from the CAI. Multiple-choice scores on content and paper ratings were indistinguishable across conditions. Perhaps student learning is more influenced by ability and motivation than the subtleties of the instructional medium. If this is the case, student satisfaction may be the preferred outcome measure for educational settings such as SuperShrink, where the objectives are broad and the background influences of ability and motivation are so strong.

How essential, then, is the computer to student satisfaction and learning in the kinds of educational experiences offered in CAI? For the SuperShrink simulation, it appears that the computer is not necessary for the high satisfaction that students report. Given that convenience was so important to student satisfaction, however, it is not known whether the computer condition would have fared better in a setting in which every student had personal access and familiarity with computers as tools for learning. The lack of difference in report quality does not allow a conclusion to be be drawn about the computer's contribution to learning in this setting.

Although these results may be largely confined to the SuperShrink simulation and have limited generalizability for evaluating the essential (versus nonessential) role of computers in promoting satisfaction or learning in other CAI simulations or tutorials, they do demonstrate the importance of evaluating $\mathrm{CAI}$ in ecologically valid settings. Laboratory or analogue studies of CAI obviously have an important role in the development of effective materials, especially in the early stages. It is essential, however, that their findings be replicated in more expensive and unpredictable field settings. Reviews of problems in analogue studies of psychotherapeutic methods came to the same conclusion more than a decade ago (Borkovec \& Rachman, 1979; Kazdin, 1978).

\section{REFERENCES}

BorKovec, T., \& RACHMAN, S. (1979). The utility of analogue research. Behaviour Research \& Therapy, 17, 253-261.

BRUNSWIK, E. (1956). Systematic and representative design of psychological experiments with results in physical and social perception (2nd ed.). Berkeley: University of California Press.

Colby, K. M. (1975). Artificial paranoia: A computer simulation of paranoid processes. New York: Pergamon.

Colby, K. M. (1980). Computer psychotherapists. In J. B. Sidowsky, J. H. Johnson, \& T. A. Williams (Eds.), Technology in mental health care delivery systems (pp. 109-117). Norwood, NJ: Ablex.

Colby, K. M., WatT, J., \& Gilbert, J. (1966). A computer method of psychotherapy: Preliminary considerations. Journal of Nervous \& Mental Disease, 142, 148-152.

Ebbesen, E. B., \& KoneCNI, V. J. (1975). Decision making and information integration in the courts: The setting of bail. Journal of Personality \& Social Psychology, 32, 805-821.

EBbesen, E. B., \& KoneCNI, V. J. (1980). On the external validity of decision-making research: What do we know about decisions in the real world? In T. S. Wallsten (Ed.), Cognitive processes in choice and decision behavior (pp.21-45). Hillsdale, NJ: Erlbaum.

KAZDIN, A. E. (1978). Evaluating the generality of findings in analogue therapy research. Joumal of Consulting \& Clinical Psychology, 46, 673-687.

Lowman, J. (1987). SuperShrink [Computer program]. San Diego: Harcourt Brace Jovanovich.

Lowman, J. (1990). SuperShrink II [Computer program]. San Diego: Harcourt Brace Jovanovich.

Lowman, J., \& Norkus, M. (1987). The SuperShrink interview: Active versus passive questioning and student satisfaction. Computers in Human Behavior, 3, 182-192.

PhILlips, M. (1989). Objective scoring of SuperShrink assessment papers. Unpublished senior honors thesis, University of North Carolina at Chapel Hill, Department of Psychology.

ROBLYER, M. D. (1985). Measuring the impact of computers in instruction: A non-technical review of research for educators. Washington, DC: Association for Educational Data Systems.

Sussman, D., \& Lowman, J. (1989). Hard-copy versus computer presentation of the SuperShrink interview simulation. Teaching of Psychology, 17, 227-230.

Weizenbaum, J. (1976). Computer power and human reason: From judgment to calculation. San Francisco: W. H. Freeman.

WinkLER, R. L., \& MURPHY, A. H. (1973). Experiments in the laboratory and the real world. Organizational Behavior \& Human Performance, 10, 252-270.

\section{NOTE}

1. SuperShrink is written in PC-PILOT and runs on MS-DOS equipment with at least $256 \mathrm{~K} \mathrm{RAM}$ and color capability. For each case, students purchase a program bundle containing two 5.25-in. diskettes (or one 3.5-in. diskette) and the SuperShrinks' Interviewing Workbook; instructors may order an Instructors' Manual containing suggested procedures and sample reports for each case.

(Manuscript received March 13, 1990; revision accepted for publication September 24, 1990.) 